\title{
ANALISIS HUBUNGAN KONFIGURASI RUANG DENGAN PENYEBARAN PENGUNJUNG PASAR KLEWER MENGGUNAKAN SPACE SYNTAX
}

\section{Dewi Nurhalimah}

Program Studi Arsitektur Fakultas Teknik Universitas Muhammadiyah Surakarta e-mail: Dnurhalimah98@gmail.com

\section{Dyah Widi Astuti}

Program Studi Arsitektur Fakultas Teknik Universitas Muhammadiyah Surakarta e-mail: dyahwidi.dw@gmail.com

\begin{abstract}
ABSTRAK
Pasar Klewer merupakan pasar tradisional yang terkenal sebagai pusat konveksi batik terbesar di Kota Surakarta. Pada tahun 2014 silam Pasar Klewer mengalami kebakaran yang mengakibatkan kerusakan cukup parah, oleh sebab itu Pasar Klewer kini telah mengalami revitalisasi dan renovasi. Kondisi Pasar Klewer kini, banyak pedagang yang menempati bangunan baru mengeluhkan penyebaran pengunjung selama ini belum merata karena pintu yang banyak diakses pengunjung hanya pada bagian sisi utara. Hal itu disebabkan tidak terbiasanya pengunjung mengakses banyak pintu masuk. Dampak dari hal tersebut adalah belum semua kios mengalami pemerataan perputaran ekonomi di bangunan baru Pasar Klewer. Penelitian ini bertujuan untuk memahami pola gerak pengunjung ditinjau dari konfigurasi ruang, penelitian ini mencoba mengungkapkan dasar pola pergerakan pengunjung dan pengaruhnya terhadap konfigurasi ruang serta pemerataan ekonomi pada setiap kios. Space Syntax digunakan sebagai alat untuk menganalisis layout denah ruang dalam bentuk gambar. Analisis tersebut ditunjukan dengan nilai intelligibility (kejelasan ruang) pada konfigurasi ruang Pasar Klewer, dimana semakin tinggi nilai syntax maka akan semakain mudah dipahami sehingga akan mendorong terjadinya aktivitas di dalamnya. Hasil analisis dideskripsikan apa adanya, kemudian dilakukan perbandingan kesesuaian dengan kondisi ruang pasar secara langsung. Hal ini diharapkan dapat meningkatkan kualitas ruang baik dari rancangan aktivitas maupun peletakan fasilitas yang dibutuhkan oleh Pasar Klewer.
\end{abstract}

KATA KUNCI: pasar klewer, penyebaran pengunjung, konfigurasi ruang

\section{PENDAHULUAN}

Pasar klewer merupakan satu tempat yang menjadi identitas kota Surakarta dimana Pasar Klewer terkenal sebagai pusat batik dan tekstil terbesar. Pada tanggal 27-28 Desember 2014, Pasar Klewer mengalami kebakaran yang cukup parah dan saat ini telah mengalami revitalisasi dan renovasi. Pasar klewer kini telah dihuni oleh ribuan pedagang dan aktivitas jual belipun sudah berjalan normal. Namun, ketika menempati bangunan yang baru, para penjual mengeluhkan penyebaran pengunjung yang belum merata. Hal ini disebabkan pintu masuk pasar yang paling banyak diakses pengunjung hanya dari satu sisi, yaitu pintu utara. Hal ini berakibat pengunjung hanya berputar di area sisi utara tanpa sedikitpun menengok ke bagian sisi lainnya, sehingga perputaran ekonomi di lokasi baru Pasar Klewer menjadi belum merata.

Dalam mendesain fasilitas komersil seperti halnya pasar tradisional, yang harus diperhatikan adalah kemudahan dalam akses sirkulasi pengunjung. Gerak pengunjung sangat mempengaruhi aktivitas suatu ruang. Berdasarkan persepsi masyarakat dalam hal ini penjual di Pasar Klewer terhadap penyebaran pengunjung, maka menjadi sangat menarik untuk diangkat dalam penelitian ini, guna mengetahui pola pergerakan pengunjung. Dilihat dari fenomena yang terjadi pada Pasar Klewer ruang dan alur pergerakan pengunjung membentuk konsentrasi yang berbeda di setiap titiknya. Hal ini menyebabkan terdapat area yang ramai dan sepi pengunjung. Pola tersebut mendasari pergerakan pengunjung yang berpengaruh pada konfigurasi ruang. Konfigurasi ruang akan memetakan penyebaran pengunjung yang erat kaitannya dengan pemerataan ekonomi pada setiap kios Pasar Klewer

Penelitian ini fokus pada pola penyebaran pengunjung yang dilihat dari konfigurasi ruangnya dengan menggunakan software space syntax. Space syntax digunakan untuk mengetahui pola pergerakan pengunjung dengan menganalisis lay out ruang dalam bentuk gambar, diantaranya ditunjukan dengan nilai intelligibility (kejelasan ruang) pada konfigurasi ruang Pasar Klewer. Semakin tinggi nilai syntax maka akan semakin mudah dipahami sehingga akan mendorong terjadinya aktivitas di dalamnya. Hasil analisis kemudian dideskripsikan apa adanya hasil dan kemudian melakukan perbandingan kesesuaian 
dengan kondisi ruang pasar secara langsung, sehingga diharapkan dapat meningkatkan kualitas ruang baik dari rancangan aktivitas maupun peletakan fasilitas yang dibutuhkan oleh Pasar Klewer.

\section{TINJAUAN PUSTAKA}

\section{Pasar Tradisional}

Pasar tradisional merupakan tempat bertemunya penjual dan pembeli secara langsung serta ditandai dengan budaya tawar menawar. Bangunan di pasar tradisional terdiri dari kios atau gerai, los dan dasaran terbuka yang dibuka penjual maupun suatu pengelola pasar.

\section{Pengguna Pasar}

Menurut Damsar (1997) pengguna pasar dikelompokan menjadi 2 yaitu pembeli dan penjual, pembeli dikelompokan lagi menjadi 3 yaitu :

1. Pengunjung adalah mereka yang datang ke pasar tanpa mempunyai tujuan untuk melakukan pembelian barang atau jasa

2. Pembeli adalah mereka yang datang ke pasar dengan maksud untuk membeli suatu barang atau jasa tetapi tidak memiliki tujuan ke mana dan dimana

3. Pelanggan adalah mereka yang datang ke pasar bermaksud untuk membeli barang atau jasa yang mempunyai tujuan kemana dan dimana akan membeli.

\section{Ruang Terpinggirkan}

Permasalahan yang sering dijumpai pada lay out ruang pasar adalah ruang terpinggirkan atau spatial marginalization (D.Dewar dan Vanessa W, 1990). Layout berhubungan dengan pergerakan pengunjung dalam sebuah pasar yang terkait dengan tata ruang los atau kios. Penyebaran dari gerakan pengunjung dipengaruhi oleh 3 faktor yaitu: lingkungan, orientasi sirkulasi yang dominan dan kontak visual. Pergerakan atau sirkualasi pasar akan berpengaruh pada seringnya atau jarangnya suatu tempat/kios/los dikunjungi atau dilewati oleh pembeli, sehingga tidak menutup kemungkinan bahwa dijumpai tempat yang mati atau jarang dikunjungi oleh pembeli .

\section{Ruang Dan Konfigurasi Ruang}

Ruang secara sederhana dapat diartikan sebagai wadah aktivitas. Beragam aktivitas membutuhkan konfigurasi ruang yang kemudian berdampak pada susunan ruang yang efektif dan efisien, yang ditentukan dari pembentukan struktur ruang.

Dalam teorinya Hillier (2007), mengungkap bahwa ruang terbentuk dari hubungan dengan ruangruang yang lain sebagai wadah aktivitas penggunanya. Dalam pendekatan ini, Hillier melihat hubungan antara ruang dan manusia (pengguna atau penghuni suatu ruang). Tidak merujuk pada hubungan penghuni dengan ruangan sebagai konfigurasi ruang secara bersamaan.

\section{Space Syntax}

Pola hubungan antar ruang dikenal dengan syntax. Syntax diartikan sebagai pola hubungan spacial yang memungkinkan konfigurasi ruang memiliki arti yang dapat dibaca atau dipahami setiap orang. Space syntax berkaitan dengan hubungan antar manusia dengan ruangan yang mereka tempati. Space syntax digunakan untuk dapat memahami ruang dalam konfigurasi terutama proses pembentukannya dan makna sosial yang disampaikan (Bafina,2003).

Space syntax laboratory menyebut bahwa space syntax merupakan sebuah perangkat teknik untuk menganalisa konfigurasi dari berbagi ruang, khususnya dimana konfigurasi ruang merupakan aspek yang penting pada hubungan sosial manusia baik dalam skala bangunan maupun skala kota.

\section{METODE PENELITIAN}

Metode penelitian ini menggunakan metode campuran yaitu metode kualitatif dan kuantitatif. Penerapan space syntax dilakukan dengan melakukan perbandingan antara pengamatan observasi denah sebagai metode dasar kualitatif dan dengan UCL DepthmapX-0.7.0 untuk menghasilkan kalkulasi hubungan ruang dan integrasi antara ruang pengamat dalam Pasar Klewer.

\section{Teknik Pengumpulan Data}

\section{Observasi}

Pertama metode pengumpulan data penelitian ini menggunakan cara observasi yaitu dengan mengamati fenomena penyebaran pengunjung Pasar Klewer. Kemudian mengumpulkan data eksisting berupa denah Pasar Klewer yang baru dan dianalisis menggunakan program spatial network depthmapX0.7.0 yang dikembangkan oleh Hillier (2007). Penelitian ini memfokuskan pada denah lantai 1, bagian sisi barat Pasar Klewer untuk mewakili seluruh penyebaran pengunjung di Pasar Klewer. Dengan menggunakan UCL depthmapX-0.7.0 menghasilkan perbedaan kedalaman analisis dengan memberikan tampilan spektrum warna merah hingga biru. Warna merah mengindentifikasikan area yang menerima pergerakan terbanyak dan paling banyak terintegrasi dengan ruang maupun jalan lain. Warna biru mengidentifikasikan area yang paling sedikit menerima pergerakan dan paling sedikit integrasi dengan ruang maupun jalan yang lain.

Kedua setelah mendapatkan hasil dari analisis UCL depthmapX-0.7.0 pengambilan data selanjutnya, 
melakukan observasi lapangan dengan mengamati dan membandingkan antara hasil analisis dengan keadaan lapangan yang didokumentasikan sehingga akan diketahui bagaimana pola pegerakan pengunjung di dalam Pasar Klewer sebenarnya.

\section{Wawancara}

Teknik wawancara digunakan sebagai cara untuk mengetahui atau memperoleh data dan informasi mengenai pemerataan ekonomi pada Pasar Klewer melalui interaksi sosial dengan narasumber. Narasumber yang dimaksud adalah titik sampling dari hasil data sekunder yang berjudul "Preferensi Ruang Kios Yang Ideal Berdasarkan Aktivitas Pedagang (Studi Kasus Pasar Klewer)" oleh Wirawati (2017), yang dikorelasikan dengan hasil analisis space syntax yang digunakan sebagai titik penentu sampling. Tabel 1 adalah beberapa pertanyaan yang digunakan untuk mendapatkan informasi dari berbagai titik sampling yang telah ditentukan.

Tabel 1. Daftar Pertanyaan

\begin{tabular}{|c|c|c|}
\hline No & Data & Pertanyaam \\
\hline \multirow[t]{3}{*}{1.} & Sekunder ${ }^{1}$ & Luas kios yang ditempati? \\
\hline & & Yang menentukan lokasi ? \\
\hline & & Omset yang didapat setiap hari? \\
\hline \multirow[t]{2}{*}{2.} & Primer ${ }^{2}$ & Rata -rata jumlah pengunjung ? \\
\hline & & Harga sewa kios yang ditentukan? \\
\hline
\end{tabular}

\section{Teknik Analisis Data}

Teknik analisis data menggunakan deskripsi komparatif data yaitu dengan melakukan perbandingan hasil analisis dengan mendeskripsikan apa adanya hasil analisis space syntax dan kemudian melakukan perbandingan pada observasi lapangan dalam konteks ruang Pasar Klewer.

\section{HASIL DAN PEMBAHASAN}

Pasar Klewer berlokasi di Jalan Radjiman, Gajahan, Pasar Kliwon, Kota Surakarta. Gambar 1 merupakan denah Pasar Klewer yang baru, dimana kini menjadi pusat perekonomian Kota Surakarta dan menjadi tempat kulakan bagi pedangan, baik dari Surakarta maupun dari berbagai kota di Indonesia. Dari desain layout denah tersebut, nantinya akan dianalisis menggunakan UCL DepthmapX-0.7.0, sehingga dapat diketahui pola pergerakan pengunjung dari konfigurasi ruangnya.

\section{Analisis Konfigurasi}

Konfigursi merupakan bentuk dari hubungan antara elemen yang berbeda dalam satu system (Hillier,2007). Bentuk konfigurasi suatu ruang dapat dinilai dari pendekatan integrasi, yaitu sebuah satuan nilai untuk mengetahui kuat lemahnya sebuah tatanan bentuk akan memudahkan dalam melihat aksesibilitas suatu sistem.

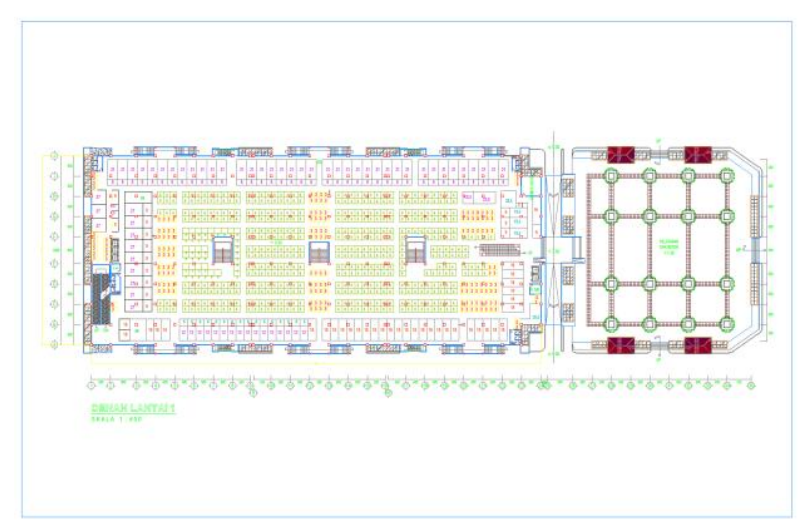

Gambar 1. Denah Pasar Klewer baru

(Sumber : Wirawati, 2017)

\section{Analisis Konektivitas}

Analisis garis axial line connectivitas dalam Gambar 2 memperlihatkan bahwa nilai konektivitas dihitung dari jumlah ruang yang tehubung menggunakan konsep jarak dan kedalaman ruang. Dari nilai tersebut dapat dilihat bahwa ruang Pasar Klewer bagian tengah terhubung langsung dengan ruang yang lainnya sehingga tingkat interaksi setiap ruang terhadap ruang-ruang yang lain tinggi. Dapat dikatakan bahwa semakin dekat jarak antar ruang maka semakin mudah bagi pengunjung untuk mengakses ruang tersebut dan kemungkinan menjadi area yang banyak diakses oleh para pengunjung pasar.

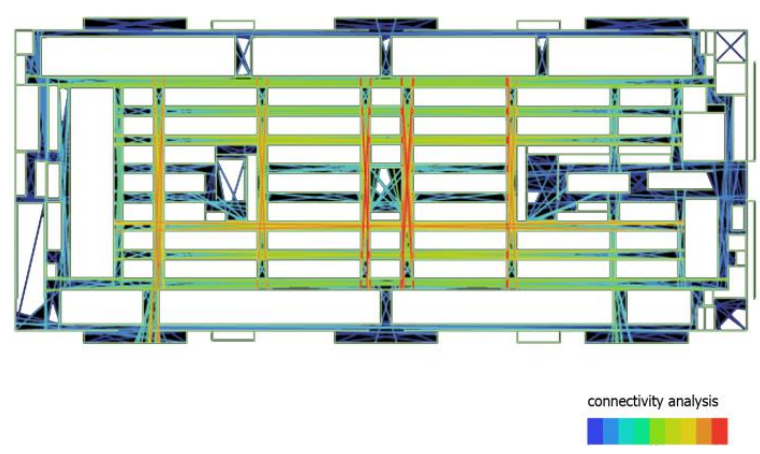

Gambar 2. Axial Line Connectivity Analisis Denah Lantai 1 Pasar Klewer (Sumber : Analisis Penulis,2019)

\section{Analisis Integrasi}

Gambar 3 merupakan hasil analisis garis axial line integrity (HH). Nilai integrasi merupakan nilai kemudahan seseorang untuk mencapai suatu ruang atau kios. Dari hasil analisis tersebut terlihat bahwa ruang pada Pasar Klewer bagian tengah memiliki integrasi yang tinggi dimana ruang-ruangnya dapat dicapai dengan mudah tanpa harus melalui sebuah ruang yang lain untuk masuk kedalam ruang atau kios. 


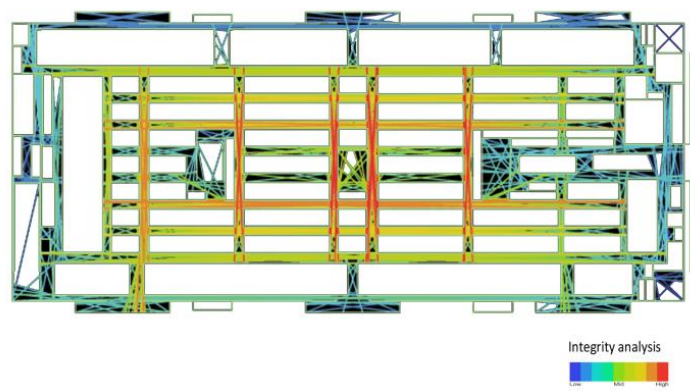

Gambar 3. Axial Line Integrasi Denah Lantai 1 Pasar Klewer (Sumber : Analisis Penulis,2019)

Area tengah pasar yang dipresentasikan dengan garis warna merah menghubungkan langsung akses masuk dan menerus dengan jalur keluar atau sebalikanya dan menghubungkan langsung dengan tangga menuju lantai atas maupun lantai semi basemen. Nilai terendah terdapat pada bangunan yang direpresentasikan warna biru. Warna biru terlihat di bagian jajaran kios paling pinggir. Nilai dengan rata-rata sedang berada pada jalur sikulasi antar ruang yang direpresentasikan warna hijau.

\section{Hubungan Konektivitas Dan Integrasi}

Hubungan antara analisis tersebut yaitu connectivity dan integrity dimana dari keduanya dapat dilihat nilai integibillity (nilai kejelasan). Semakin kuat hubungan dari kedua variabel tersebut maka sebuah ruang akan semakain mudah dikenali.

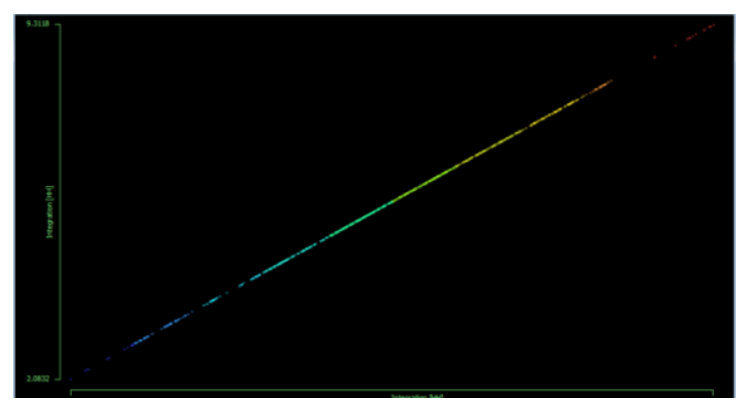

Gambar 4. Axial Line Integibillity Denah Lantai 1 Pasar Klewer (Sumber : Analisis Penulis, 2019)

Pada gambar 4 menandakan bahwa pola ruang Pasar Klewer membentuk pola grid, dapat dikatakan nilai inteligibillity dari konfigurasi ruang Pasar Klewer bagian tengah menunjukan konektivitas yang tinggi. Gambar tersebut mempunyai arti yaitu kemudahan dalam pencapaian ruang, dimana ruang tengah Pasar Klewer memiliki nilai integritas tinggi, sehingga ruangruangnya cenderung mudah dijangkau.

Apabila dikaitkan dengan teori natural movement (Hillier et al, 1993), ruang tengah Pasar Klewer adalah ruang yang dapat dihipotesiskan sebagai ruang paling banyak ditemukan aktivitas pengunjung. Sebaliknya ruang-ruang yang menunjukan integibillity rendah biasanya berada pada area paling jauh atau terpinggirkan karena konektivitas pada ruang yang lain lebih jauh. Dapat disimpulkan bahwa pejalan kaki atau pengunjung cenderung memilih akses jalur yang mudah dijangkau dan mudah dilihat.

\section{Analisis Hasil Observasi}

Observasi pada Pasar Klewer dilakukan dengan cara pengamatan langsung pada hari operasional pasar di hari biasa dan hari akhir pekan. Pengamatan langsung dilakukan dengan mendokumentasikan keramaian pengunjung pada area yang disesuaikan dengan hasil analisis space syntax. Gambar 5-7 menunjukkan titiktitik observasi.

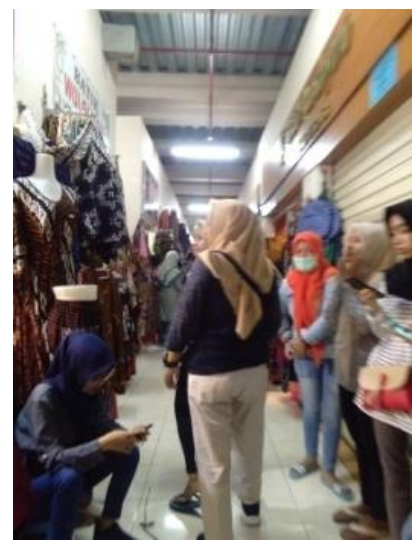

Gambar 5. Titik Observasi 1

(Sumber: Analisis Penulis, 2019)

Observasi lapangan yang pertama dilakukan pada area yang yang disesuaikan dengan hasil analisis space syntax dari spektrum warna merah dapat dilihat secara umum bahwa sirkulasi pada area ini cukup luas memudahkan pengunjung untuk mengakses dan melihat barang dagangan, serta banyak pengunjung di area ini.

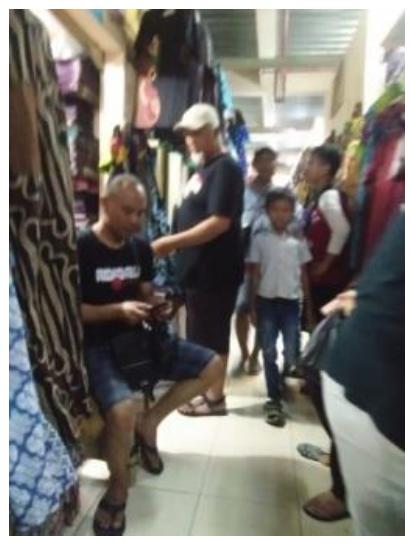

Gambar 6. Titik Observasi 2

(Sumber: Analisis Penulis, 2019)

Gambar 6 adalah hasil observasi lapangan yang disesuaikan dengan hasil analisis space syntax dari 
spektrum warna hijau-kuning. Dapat dilihat secara umum bahwa sirkulasi pada area ini lebih sempit sehingga pengunjung tidak leluasa untuk melihat barang dagangan.

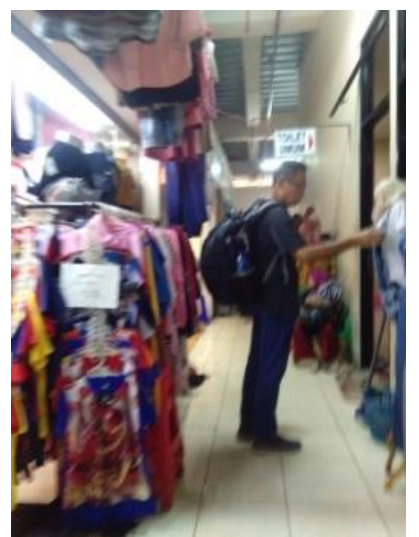

Gambar 7 Titik Observasi 3

(Sumber: Analisis Penulis, 2019)

Gambar 7 merupakan hasil observasi lapangan yang disesuaikan dengan hasil analisis Space Syntax dari spektrum warna biru. Dapat dilihat secara umum bahwa sirkulasi pada area ini cukup luas memudahkan pengunjung untuk mengakses dan melihat barang dagangan.

\section{Analisis Dan Interpretasi}

Hasil observasi lapangan akan dilanjutkan dengan mengkorelasikannya dengan hasil space syntax. Pada penelitian kali ini yang akan diamati adalah pengaruh penyebaran pengunjung terhadap titik sampling untuk mengetahui pengaruh perputaran ekonomi di Pasar Klewer sekarang ini.

1. Lokasi 1 Area Spektrum Warna Merah (High Integration)

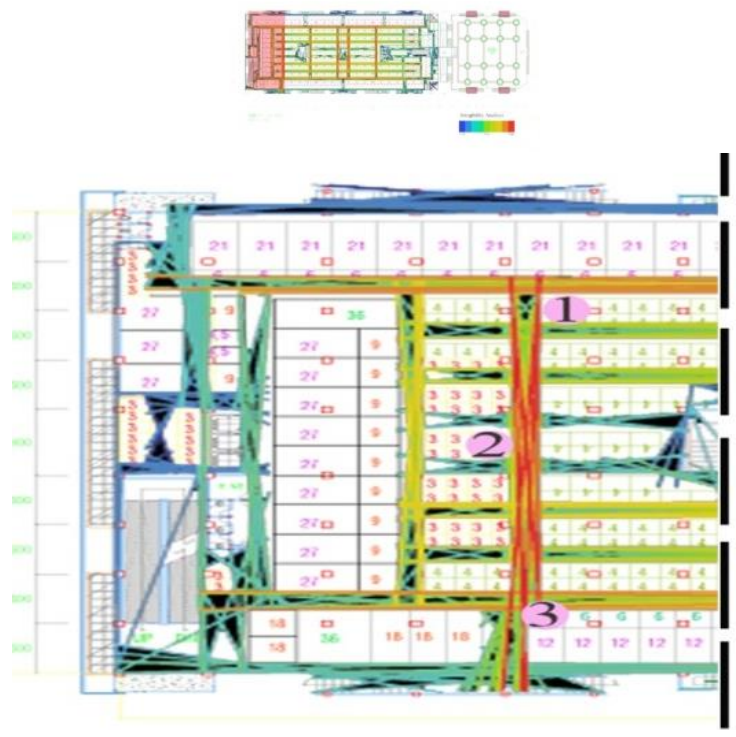

Gambar 8. High Integration (Sumber: Analisis Penulis, 2019)
Titik Sampling Ke-1

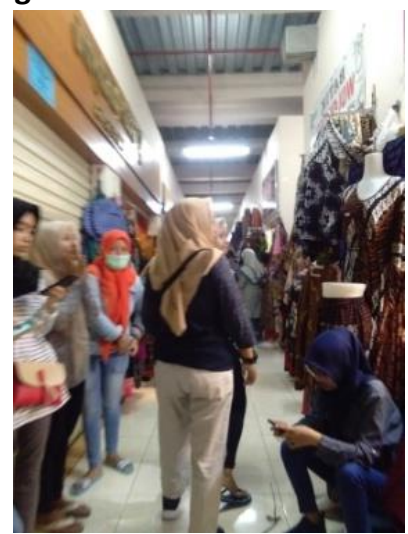

Gambar 9. Titik Sampling 1

(Sumber : Analisis Penulis,2019)

Titik sampling 1 ramai dilalui pengunjung, sirkulasi cukup luas, pengunjung dapat melihat barang dagangan dari luar maupun dari dalam kios. Kios merupakan tipe sedang (tipe B) harga kios \pm 50 juta rupiah, dengan jumlah rata-rata pengujung 90-120 orang, omset perhari sekitar \pm 20 juta rupiah.

\section{Titik Sampling Ke-2}

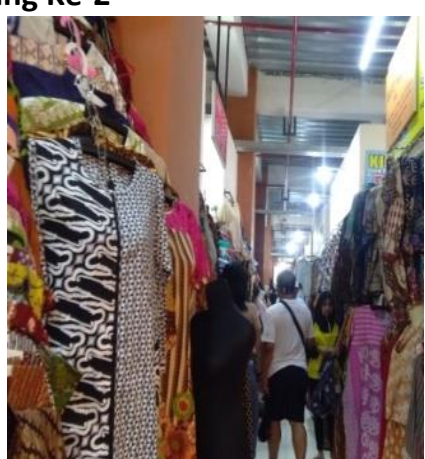

Gambar 10. Titik Sampling 2

(Sumber : Analisis Penulis,2019)

Titik sampling 2 ramai dilalui pengunjung, barang dagangan memenuhi jalur sirkulasi sehingga sirkulasi tidak lancar,pengunjung hanya dapat melihat barang dari luar.Kios merupakan tipe kecil (tipe c) harga kios \pm 9 juta rupiah, dengan jumlah rata-rata pengujung 100 -110 orang, omset perhari sekitar \pm 20 juta rupiah.

Titik Sampling ke-3

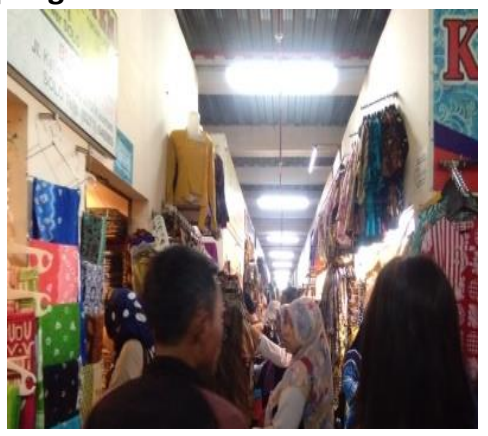

Gambar 11. Titik Sampling 3

(Sumber : Analisis Penulis,2019) 
Titik sampling 3 ramai dilalui pengunjung, barang dagangan memenuhi jalur sirkulasi sehingga sirkulasi tidak lancar, pengunjung hanya dapat melihat barang dari luar. Kios merupakan tipe kecil (tipe c) harga kios \pm 15 juta rupiah, dengan jumlah rata-rata pengujung 90-120 orang, omset perhari sekitar \pm 30 juta rupiah.

Tabel 2. Korelasi Hasil Analisis Space Syntax dan Observasi

\begin{tabular}{lllll}
\hline Kios $^{1}$ & $\begin{array}{l}\text { Tingkat } \\
\text { keramaian }\end{array}$ & $\begin{array}{l}\text { lapangan } \\
\text { Rata-rata } \\
\text { jumlah } \\
\text { pengunjung }\end{array}$ & $\begin{array}{l}\text { Omset } \\
\text { perhari' } \\
\text { (Rp) }\end{array}$ & $\begin{array}{l}\text { Harga } \\
\text { sewa } \\
\text { kios }^{2} \text { (Rp) }\end{array}$ \\
\hline Tipe A & Ramai & $90-120$ & \pm 20 juta & \pm 50 juta \\
\hline Tipe C & $\begin{array}{l}\text { Cukup } \\
\text { ramai }\end{array}$ & $100-110$ & \pm 20 juta & $\begin{array}{l} \pm 9 \\
\text { juta }\end{array}$ \\
\hline Tipe B & $\begin{array}{llll}\text { Cukup } \\
\text { ramai }\end{array}$ & $90-120$ & \pm 30 juta & $\begin{array}{l} \pm 15 \\
\text { juta }\end{array}$ \\
\hline
\end{tabular}

(Sumber data : ${ }^{1}$ Wirawati. K, (2017) , ${ }^{2}$ Wawancara Penulis,(2019)

\section{Lokasi 2 Area Spektrum Warna kuning-hijau (Medium Integration)}

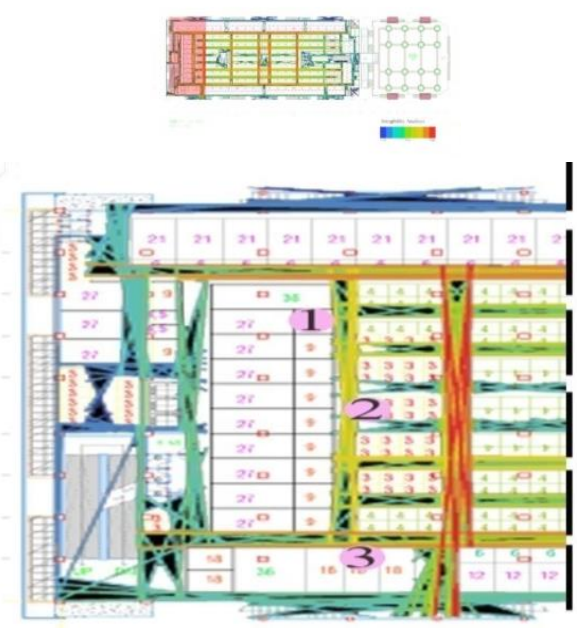

Gambar 12. Medium Integration (Sumber: Analisis Penulis, 2019

\section{Titik Sampling Ke-1}

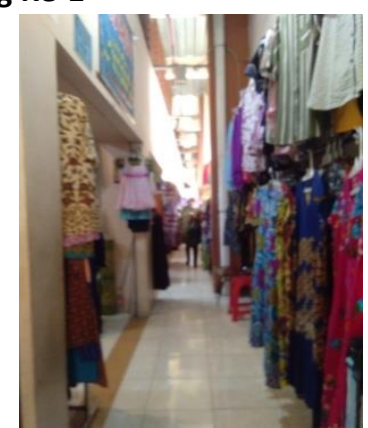

Gambar 13. Titik Sampling 1

(Sumber : Analisis Penulis,2019)

Titik sampling 1 tidak ramai pengunjung, jalur sirkulasi sempit, pengunjung dapat masuk ke dalam kios untuk melihat barang dagangan. Kios berukuran sedang (tipe B). Harga kios \pm 15 juta rupiah, dengan jumlah rata-rata pengujung 90-100 orang, omset perhari sekitar \pm 18 juta rupiah.

\section{Titik Sampling Ke-2}

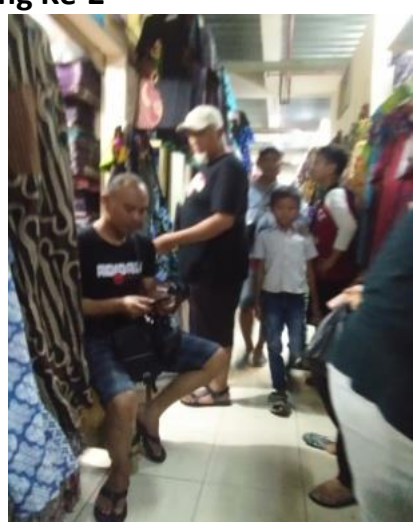

Gambar 14. Titik Sampling 2

(Sumber : Analisis Penulis,2019)

Titik sampling 2 ramai pengunjung, jalur sirkulasi sempit, pengunjung hanya dapat melihat barang dari luar. Kios merupakan kios tipe C (kecil), harga kios \pm 9 juta rupiah, dengan jumlah rata-rata pengujung 80100 orang, omset perhari sekitar \pm 16 juta rupiah.

\section{Titik Sampling ke-3}

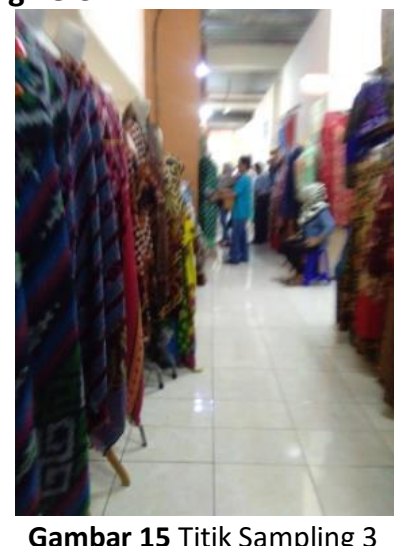

(Sumber : Analisis Penulis, 2019)

Titik sampling 3 ramai pengunjung, jalur sirkulasi cukup luas, pengunjung hanya dapat melihat barang dari luar. Kios merupakan kios tipe A (Besar). Harga kios $\pm 50 j u t a$ rupiah, dengan jumlah rata-rata pengujung 90-120 orang, omset perhari sekitar \pm 19 juta rupiah.

Tabel 3. Korelasi Hasil Analisis Space Syntax dan Observasi

\begin{tabular}{lllll}
\hline Kios' $^{1}$ & $\begin{array}{l}\text { Tingkat } \\
\text { keramaian }\end{array}$ & $\begin{array}{l}\text { Rata-rata } \\
\text { jumlah } \\
\text { pengunjung }\end{array}$ & $\begin{array}{l}\text { Omset } \\
\text { perhari' } \\
(\mathbf{R p})\end{array}$ & $\begin{array}{l}\text { Harga } \\
\text { sewa } \\
\text { kios }^{2} \text { (Rp) }\end{array}$ \\
\hline Tipe A & Ramai & $90-120$ & \pm 19 juta & \pm 50 juta \\
\hline Tipe C & $\begin{array}{l}\text { Cukup } \\
\text { ramai }\end{array}$ & $80-100$ & \pm 16 juta & \pm 9 juta \\
\hline Tipe B & $\begin{array}{l}\text { Cukup } \\
\text { ramai }\end{array}$ & $90-100$ & \pm 18 juta & \pm 15 juta \\
\hline
\end{tabular}

(Sumber Data : ${ }^{1}$ Wirawati. K , (2017) , ${ }^{2}$ Wawancara Penulis,(2019) 


\section{Lokasi 3 Area Spektrum Warna Biru} (Low Integration)

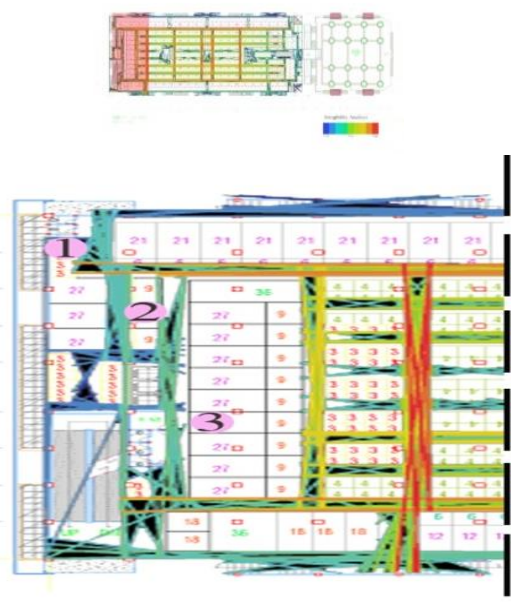

Gambar 16 Low Integration

(Sumber: Analisis Penulis, 2019)

\section{Titik Sampling Ke-1}

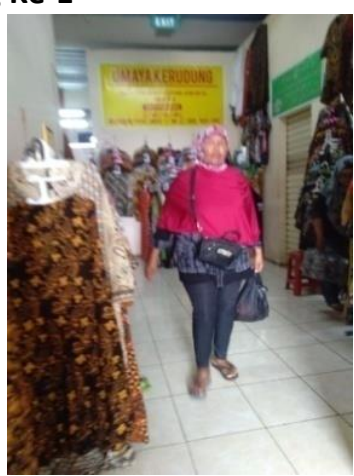

Gambar 17. Titik Sampling 1

(Sumber : Analisis Penulis,2019)

Titik sampling 1 area sirkulasi luas, namun kurang ramai pengunjung, kios berukuran kecil ( tipe c), dekat dengan toilet umum. Pengunjung tidak dapat masuk untuk melihat barang dagangan. Harga sewa kios \pm 9 juta rupiah dengan jumlah rata-rata pengujung 80-100 orang, omset perhari sekitar \pm 15 juta rupiah.

\section{Titik Sampling Ke-2}

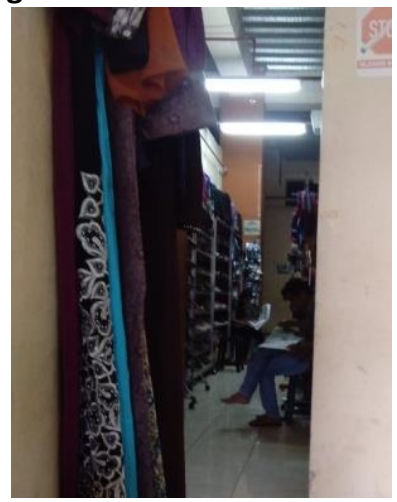

Gambar 18. Titik Sampling 2

(Sumber : Analisis Penulis,2019)
Titik sampling 2 area sirkulasi sangat sempit, kurang ramai pengunjung. Kios berukuran sedang (tipe B) dekat dengan toilet umum. Harga kios \pm 15 juta rupiah, dengan jumlah rata-rata pengunjung $80-100$ orang, omset perhari sekitar \pm 15 juta orang.

\section{Titik Sampling Ke-3}

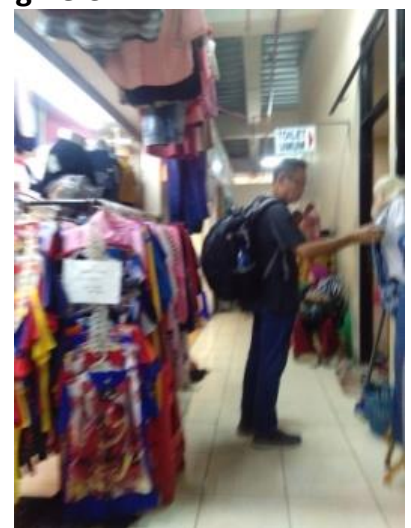

Gambar 19. Titik Sampling 3

(Sumber : Analisis Penulis,2019)

Titik sampling 3 area sirkulasi cukup luas,cukup ramai pengunjung. Kios berukuran besar (tipe A), pengunjung dapat masuk untuk melihat barang dagangan, dekat dengan toilet umum. Harga kios \pm 50 juta rupiah, dengan jumlah rata-rata pengujung 90100 orang dan omset perhari sekitar \pm 50 juta rupiah.

Tabel 4. Korelasi Hasil Analisis Space Syntax dan Observasi

\begin{tabular}{|c|c|c|c|c|}
\hline Kios $^{1}$ & $\begin{array}{l}\text { Tingkat } \\
\text { keramaian² }\end{array}$ & $\begin{array}{l}\text { Rata-rata } \\
\text { jumlah } \\
\text { pengunjung }{ }^{1}\end{array}$ & $\begin{array}{l}\text { Omset } \\
\text { perhari' } \\
\text { (Rp) }\end{array}$ & $\begin{array}{l}\text { Harga } \\
\text { sewa } \\
\text { kios }^{2} \text { (Rp) }\end{array}$ \\
\hline Tipe A & $\begin{array}{l}\text { Cukup } \\
\text { ramai }\end{array}$ & $80-100$ & $\pm 15 \mathrm{Jt}$ & \pm 9 juta \\
\hline Tipe C & $\begin{array}{l}\text { Cukup } \\
\text { ramai }\end{array}$ & $50-70$ & $\pm 10 \mathrm{jt}$ & \pm 50 juta \\
\hline Tipe B & $\begin{array}{l}\text { Cukup } \\
\text { ramai }\end{array}$ & $80-100$ & $\pm 18 \mathrm{jt}$ & \pm 15 juta \\
\hline
\end{tabular}

Sumber data : ${ }^{1}$ Wirawati. K , (2017) , ${ }^{2}$ Wawancara Penulis,(2019)

Dari hasil korelasi antara data analisis space syntax dan data observasi lapangan dapat dilihat bahwa pola sirkulasi pengunjung Pasar Klewer menunjukkan kebanyakan pengunjung memilih jalur akses yang mudah dicapai antara ruang satu dengan yang lain. Penyebab lain pola sirkulasi keramaian pengunjung, disebabkan oleh sempitnya jalur sirkulasi mengakibatkan sirkulasi yang tidak lancar. Dari observasi titik sampling, dapat dilihat bahwa penyebaran pengunjung tidak mempengaruhi omset pendapatan penjual dan juga tidak mempengaruhi terhadap harga sewa kios, karena penempatan pedagang tidak memilih secara mandiri akan tetapi sudah ditentukan dari pihak pengelola. 


\section{KESIMPULAN}

Konfigurasi layout Pasar Klewer membentuk pola grid dimana pola grid membentuk nilai intigibility di tengah ruang tinggi dan nilai yang lebih rendah di area pinggir ruang, sehingga yang mendasari pola pergerakan pengunjung Pasar Klewer adalah jarak dan kemudahan akses antar ruang.

Dilihat dari korelasi antara data analisis space syntax dan data lapangan maka dapat disimpulkan bahwa konfigurasi ruang mempengaruhi penyebaran pola sirkulasi pada Pasar Klewer sesuai dengan data analisis space syntax, dimana kebanyakan pengunjung memilih jalur akses yang mudah dicapai antara ruang satu dengan yang lain.

Hasil antara observasi space syntax dan observasi lapangan berkaitan dengan penyebaran pengunjung dan pengaruhnya terhadap omset pendapatan, ternyata hal ini tidak berpengaruh drastis terhadap pendapatan penjual. Pada kenyataannya teknologi saat ini dapat menjadi pilihan lain untuk berdagang selain di pasar. Penyebaran pengunjung juga tidak berpengaruh terhadap harga sewa kios sebab penentuan lokasi kios sudah ditetapkan oleh pihak pengelola.

Saran yang dapat diberikan dalam penelitian ini adalah kesadaran bahwa keberadaan pasar tradisional pada dasarnya masih dibutuhkan masyarakat, tetapi keberadaannya perlu perencanaan yang tepat dan koordinasi dalam penataan kios, agar pemerataan pengunjung lebih merata.

Nilai sintaks intelligibility dapat digunakan sebagai dasar dalam merumuskan alternatif-alternatif rancangan konfigurasi ruang pasar dengan mempertimbangkan beberapa hal terkait kemudahan dalam akses pengunjung dan dalam pelaksanaan pembangunan pasar.

\section{DAFTAR PUSTAKA}

Bafna, S. (2003). Space Syntax: A Brief Introduction to its Logic and Analytical Techniques. Environment and Behavior

Bill Hillier. (2007). Space is the machine: A configurational theory of architecture, Press Syndicate of the University of Cambridge

Barada, W. P. (2013). Analisis Space Syntax Rumah Susun Berbasis Gang Kampung. Prosiding Simposium Nasional Rekayasa Aplikasi Perancangan dan Industri (RAPI).

David Dewar and Vanessa Watson. (1990). Urban Market Developing Informal Retailing, London, Rontledge

Damsar. (1997). Sosiologi Ekonomi. Bielefeld: PT Raja Grafindo Persada
Darjosanjoto, E. T. (2006). Penelitian Arsitektur di Bidang Perumahan dan Permukiman.Surabaya: ITS Press.

Hillier, B., \& Hanson, J. (1989). The Social Logic of Space. USA: Cambridge University Press.

Nazir, I. R., \& Iman, M. Fenomena Pasar Kaget: Hibriditas Sistem Pasar Tradisional Di Ruang Kota. Jurnal SCALE, 5(2), 9-9, 2018.

Rahantoknam, S., Tondobala, L., \& Tarore, R. C. (2015). Pemanfaatan Ruang Para Pedagang Di Pasar Tradisional Bahu, Manado Dan Pengaruhnya Terhadap Kondisi Aksesibilitas Kawasan. SPASIAL, 2(3), 131-141.

Romdhoni, M. F. (2018). Analisis Pola Konfigurasi Ruang Terbuka Kota Dengan Penggunaan Metoda Space Syntax Sebagai Spatial Logic Dan Space Use. NALARs, 17(2), 113-128.

Siregar, J. P. (2014). Metodologi Dasar Space Syntax Dalam Analisis Konfigurasi Ruang. Malang: Universitas Brawijaya.

Turner, A. (2007). UCL Depthmap 7: From Isovist Analysis To Generic Spatial Network Analysis. New Developments In Space Syntax Software, Istanbul Technical University, 43-51.

Widyawati. K. (2016). Pengaruh Konfigurasi Spasial dan Jaringan Sosial terhadap Durasi Aktif Ruang Kota pada Fenomena Pasar Temporer Cijantung. IPLBI, E 097.

Wirawati,. K (2017). Prefrensi Ruang Kios Yang Ideal Berdasarkan Aktivitas Pedagang (Studi Kasus: Pasar Klewer). Seminar Penelitian. Universitas Muhammadiyah Surakarta.

Yudhanta, W. C. (2018). Pengaruh Konfigurasi dan Visibilitas Ruang pada Aksesibilitas, Studi Kasus pada Kawasan XT Square YOGYAKARTA. Jurnal Arsitektur KOMPOSISI, Vol 12, No 1 pp. 67-76, 